\title{
Age and adjustment to night work
}

\author{
Mikko I Härmä, Tarja Hakola, Torbjörn Åkerstedt, Jarmo T Laitinen
}

\begin{abstract}
Objective-The study was designed to examine the effects of age on sleep and the circadian rhythms during consecutive night shifts.

Methods-Two groups of letter sorters $(19-29(n=7)$ and 53-59 $(n=7)$ years of age were studied in a sleep laboratory under closely controlled conditions. After two baseline days, circadian adjustment to three night shifts was monitored by continuous measurement of rectal temperature, salivary melatonin, and sleepwakefulness during the night shifts.

Results-Age was significantly related to the adjustment to night work of rectal temperature minimum and of self rated sleepiness. Young subjects delayed their temperature phase and decreased sleepiness more than the older subjects. Age was also significantly related to an increase of alertness and to the feeling of being refreshed after the day sleep. Although there were basic differences in sleep duration and structure between the age groups, the latter did not change across the night shifts.
\end{abstract}

Conclusion-Ageing decreases the ability to recover after several, but not after the first night shift.

(Occup Environ Med 1994;51:568-573)

In many questionnaire studies, ageing has been found to increase adverse health effects of shiftwork, the critical age being 40-50 years. ${ }^{1-3}$ One mechanism in this process may be changes in circadian rhythmicity, as ageing decreases the amplitude of many circadian rhythms, including the rhythm of pineal hormone melatonin, ${ }^{4}$ and increases the tendency to internal desynchronisation. ${ }^{5}$ Re-evaluation of older isolation studies with "free-running" conditions has shown internal desynchronisation with a shortening of the activity rhythm. ${ }^{6}$ Under normal conditions, ageing is connected to increased "morningness" 3 and a phase advance of the general activity rhythm. ${ }^{7}$

The main effects of ageing on sleep are a general decrease in the slow wave activity of the electroencephalogram (EEG) and an increase in the number and duration of arousals from sleep. ${ }^{8}$ Experimental studies on the effects of sleep deprivation on sleepiness and performance efficiency in middle aged subjects have come to rather controversial conclusions. Fröberg et $a l^{9}$ found that middle aged military personnel were less sensitive to sleep loss than younger subjects whereas Webb and Agnew ${ }^{10}$ reported that older university faculty members were more sensitive to sleep deprivation than younger volunteers. Bonnet and Rosa ${ }^{11}$ concluded that the recovery of performance of healthy 55-71 year old subjects after 64 hours of total sleep deprivation was no slower than that of younger subjects despite very different sleep recovery patterns.

The age differences in sleep duration and alertness during continuous night work could be caused by circadian factors or changes in the restorative effect of sleep. There seems to be, however, a lack of controlled laboratory studies in which both the circadian adjustment and the change of the sleep-wakefulness rhythm have been measured simultaneously. In earlier field studies, indications of a slower circadian adjustment of the oral temperature circadian rhythm in middle aged shift workers have been found. ${ }^{1213}$ Furthermore, another field study with EEG methods showed that ageing was associated with increased amounts of stage shifts, awakenings, and stage 1 sleep. ${ }^{14}$ The limited experimental data on physiological sleep tendency and performance also suggest that middle aged subjects (over 40 years) would tolerate experimental shiftwork less than younger subjects. ${ }^{15} 16$ The aim of the present study was to examine the relation between age and the adjustment of circadian rhythms, sleep, and wakefulness to consecutive night shifts.

\section{Methods}

SUBJECTS AND DESIGN

Young and older experienced letter sorters were studied in a sleep laboratory. The mean age of the young subjects was 24 (range $19-29, \mathrm{n}=7$ ) and that of the older subjects 57 (range 53-59, $\mathrm{n}=7$ ) years (table 1). Both groups comprised three men and four women.

The subjects spent five days and nights in the sleep laboratory, with the facilities of two noise dampened sleep chambers and separate

Table 1 Age, shiftwork experience, weight, and body mass index (BMI) of the young $(n=7$ ( 3 men $/ 4$ women)) and older ( $n=7$ (3 men/4 women $))$ subjects

\begin{tabular}{|c|c|c|}
\hline & $\begin{array}{l}\text { Young group } \\
\text { Mean (SD) (range) }\end{array}$ & $\begin{array}{l}\text { Older group } \\
\text { Mean (SD) (range) }\end{array}$ \\
\hline $\begin{array}{l}\text { Age (y) } \\
\text { Shiftwork } \\
\quad \text { experience (y) }\end{array}$ & $\begin{array}{rlc}23 \cdot 7 & (4 \cdot 2) & (19-30) \\
2 \cdot 8 & (2 \cdot 2) & (0-6)\end{array}$ & $\begin{array}{lr}56 \cdot 7 \quad(2 \cdot 0) & (53-59) \\
17 \cdot 3(13 \cdot 2) & (2-38)\end{array}$ \\
\hline $\begin{array}{l}\text { Weight }(\mathbf{k g}) \\
\mathrm{BMI}\left(\mathrm{kg} / \mathrm{m}^{2}\right)\end{array}$ & $\begin{array}{l}76 \quad(19) \\
25 \cdot 0 \quad(5 \cdot 7)\end{array}$ & $\begin{array}{l}74(17) \\
25 \cdot 9\end{array}$ \\
\hline
\end{tabular}


rooms for work and leisure. The subjects came to the laboratory on Sunday evening for a habituation night (fig 1). A day shift (0900-1600) was scheduled on Monday and the next three days included night shifts (2300-0530). On Friday, the subjects could leave the laboratory after sleep (after 1500).

The subjects slept in comfortable bedrooms shielded from noise and external light. Sleep was scheduled between 1030 and 0630 after the day shift and from 0630 to 1430 after the night shifts. The windows were darkened from sunlight up to 1500 after the night shifts. The light intensity was below 500 lux in the laboratory.

Controlled letter sorting, mimicking that of the routine work of these subjects, was carried out in the laboratory. Letters were delivered to the laboratory and later collected by the post delivery workers. During the experimental week, the subjects were not allowed to nap, jog, or drink alcohol. Mealtimes were kept regular. Leisure time could be spent watching $T V$, reading, doing needlework etc.

\section{RECTAL TEMPERATURE}

Rectal temperature $\left(T_{\text {re }}\right)$ was measured continuously every three minutes with a thermistor probe (YSI 401, Yellow Springs Instruments, USA) inserted $10 \mathrm{~cm}$ into the rectum. Mean temperature values were calculated for every 30 minutes to smooth the fluctuation of $T_{\mathrm{re}}$. The time of minimum $T_{\mathrm{re}}$ was estimated for each 24 hour period from the smoothed data by visual inspection.

\section{SALIVARY MELATONIN}

Salivary melatonin was assessed every hour during the night shifts. Unstimulated saliva $(2.5 \mathrm{ml})$ was collected into polyethylene tubes and stored in a freezer $\left(-20^{\circ} \mathrm{C}\right)$. Salivary melatonin was determined after chloroform extraction (described by Härmä et al ${ }^{17}$ with a modification of a radioimmunoassay described by Miles et al. ${ }^{18}$

\section{SLEEP DURATION AND STRUCTURE}

Time in bed and autonomic sleep phases were registered by the static charge sensitive-bed method $\left(\mathrm{SCSB}^{19}\right)$ during each period of sleep in the laboratory. From the SCSB, the ballistocardiogram, respiratory movements, and movements specific for postural changes can be registered simultaneously by selective filtering of the original signal. After AD conversion, the different movement frequencies were analysed (BR11, Biorec Oy, Finland). Based on the regularity of the ballistocardiogram, respiration, and body movements shorter than 10 seconds, the program calculates the autonomic activity index. Based on this index, sleep was classified into the autonomic sleep phases of active, intermediate, and quiet sleep in periods of three minutes. ${ }^{20}$

In healthy subjects, the autonomic activity level registered by the SCSB has been found to reflect NREM and REM sleep ${ }^{21}$ as well as subjective sleep quality and alertness before going to bed. ${ }^{23}$ According to a validation study of seven of the presently studied subjects ${ }^{24}$ $76 \%$ of the three-minute periods of quiet sleep could be classified as periods with a high delta activity ( $>25 \mu \mathrm{V}$ average activity) by a simultaneous EEG $(\mathrm{Cz}-\mathrm{Oz})$ recording. The mean correlation between autonomic activity index and delta activity was -0.51 in the combined REM and non-REM sleep and -0.46 in non-REM sleep. The relation between autonomic activity index and delta activity does not seem to be linear enough for defining delta activity by SCSB at a certain time point. SCSB seems, however, to be a useful method for comparative sleep quality studies.

The time of falling asleep was estimated according to the appearance of the first phase of quiet sleep for three minutes or, if the subject's personal assessment of the sleep latency was considerably different, was estimated according to subjective sleep latency and the autonomic sleep variables: movement time, ballistocardiogram slow variation, and mean respiratory movement amplitude.

PERCEIVED QUALITY OF SLEEP AND SLEEPINESS Subjective sleep quality was studied every day by a sleep log. The following questions were used. ${ }^{25}$

1 How did you sleep? ( 1 very badly -5 very well).

2 Did you feel rested after waking up? (1 not at all -5 fully rested).

3 Was your sleep disturbed or restless? (1 very -5 not at all)

4 How many times did you wake up?

5 Did you wake up "too early" without being able to fall asleep again ( 1 far too early -5 not at all too early).

6 Was it hard for you to fall asleep? (1 very hard- 5 not at all).

7 Was it hard for you to wake up (1 very hard -5 very easy).

8 Upon getting out of bed you were: 13 extremely alert-1 extremely tired.

Figure 1 Study design.

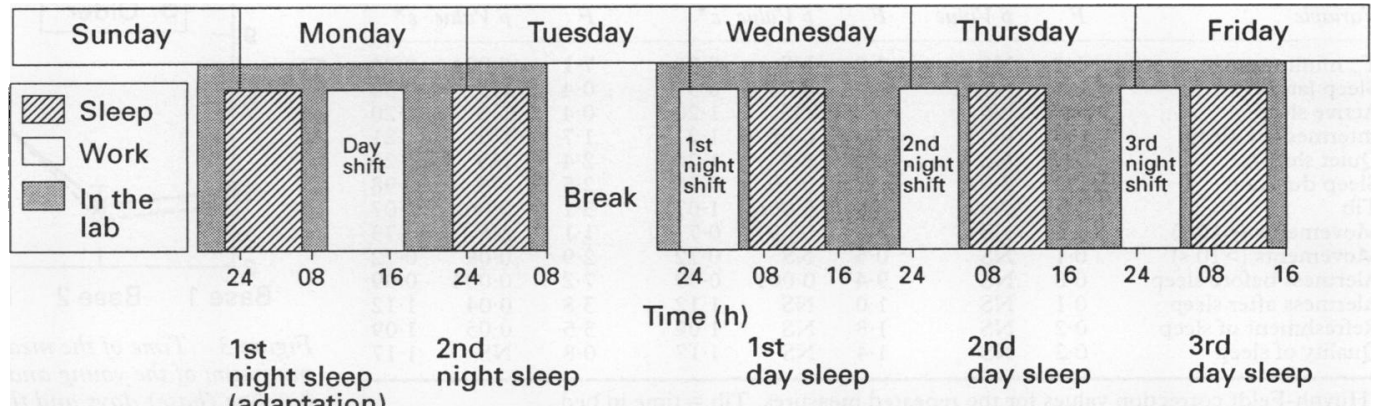


The answers to the questions 1,3 , and 4 were used to get a sleep quality index and the answers to the questions 2,7 , and 8 were used as an indication of the refreshing effect of sleep.

Subjective alertness was studied every hour during the work shifts by the Karolinska Sleepiness Scale $^{26}$ (KSS), which is a modification of the Stanford Sleepiness Scale. The KSS includes the following steps: extremely alert (score $=1$ ), alert (3), neither alert nor sleepy (5), sleepy-but no difficulty remaining awake (7), extremely sleepy-fighting sleep (9).

\section{STATISTICAL METHODS}

The effects of age, the position of the night shift, time of shift, and their interactions were studied on sleep-wakefulness, $T_{r e}$ minimum and salivary melatonin by two and three way analyses of variance (ANOVA) with repeated measures. ${ }^{27}$ As repeated measures designs usually violate the requirements of compound symmetry, the Huynh-Feldt ${ }^{28}$ corrected probabilities were used for all variables. This correction was selected as it has been shown that the Greenhouse-Geisser estimate tends to be biased downward in small samples. ${ }^{28}$ Uncorrected degrees of freedom are given together with the $F$ value, the Huynh-Feldt corrected $\mathrm{p}$ value, and the Huynh-Feldt estimator $(\varepsilon)$. Because the Huynh-Feldt $\varepsilon$ may be greater than 1 (outside the range), a value of 1 is used in these cases in all calculations for probabilities (no adjustment).

\section{Results}

BODY TEMPERATURE ( $T_{\text {re }}$ ) MINIMUM

In young letter sorters, the minimum of $T_{r e}$ was delayed about two hours (from 0736 to 0953) during the three night shifts (fig 2). By contrast, the minimum $\mathrm{T}_{\mathrm{re}}$ in older sorters advanced about one hour (from 0740 to 0635). The greatest change between the groups occurred during the third night shift (fig 3). There were no significant main effects of age or day (night shifts) on the minimum of $T_{\mathrm{re}}$ but the interaction between age and day was significant $(\mathrm{p}<0.004$, table 2$)$ indicating faster circadian adjustment of the young letter sorters.

Table 2 Results of analyses of variance with repeated measures on indicated experimenta variables: effects of age, day (night shift), time of the shift and their interactions

\begin{tabular}{|c|c|c|c|c|c|c|c|c|}
\hline \multirow[b]{2}{*}{ Variable } & \multicolumn{2}{|c|}{$\begin{array}{l}A g e \\
d f=1 / 12\end{array}$} & \multicolumn{3}{|c|}{$\begin{array}{l}D a y \\
d f=2 / 24\end{array}$} & \multicolumn{3}{|c|}{$\begin{array}{l}A g e^{\star} \text { Day } \\
d f=2 / 24\end{array}$} \\
\hline & $F$ & p Value & $F$ & p Value & $\varepsilon^{*}$ & $F$ & p Value & $\varepsilon^{*}$ \\
\hline $\begin{array}{l}\mathrm{T}_{\text {re }} \text { minimum } \\
\text { Sleep latency } \\
\text { Active sleep } \\
\text { Intermediate sleep } \\
\text { Quiet sleep } \\
\text { Sleep duration } \\
\text { Tib } \\
\text { Movements }(<10 \mathrm{~s}) \\
\text { Movements }(>10 \mathrm{~s}) \\
\text { Alertness before sleep } \\
\text { Alertness after sleep } \\
\text { Refreshment of sleep } \\
\text { Quality of sleep }\end{array}$ & $\begin{array}{l}1 \cdot 2 \\
0 \cdot 1 \\
0 \cdot 4 \\
6 \cdot 3 \\
2 \cdot 5 \\
7 \cdot 0 \\
7 \cdot 5 \\
2 \cdot 8 \\
0 \cdot 1 \\
0 \cdot 8 \\
0 \cdot 1 \\
0 \cdot 2 \\
0 \cdot 2\end{array}$ & $\begin{array}{l}\text { NS } \\
\text { NS } \\
\text { NS } \\
0.03 \\
\text { NS } \\
0.02 \\
0.02 \\
\text { NS } \\
\text { NS } \\
\text { NS } \\
\text { NS } \\
\text { NS } \\
\text { NS }\end{array}$ & $\begin{array}{l}1 \cdot 2 \\
4 \cdot 4 \\
1 \cdot 7 \\
2 \cdot 8 \\
0 \cdot 1 \\
2 \cdot 7 \\
6.5 \\
3 \cdot 0 \\
0 \cdot 5 \\
9 \cdot 4 \\
1 \cdot 0 \\
1 \cdot 8 \\
1 \cdot 4\end{array}$ & $\begin{array}{l}\text { NS } \\
0 \cdot 05 \\
\text { NS } \\
0 \cdot 08 \\
\text { NS } \\
0 \cdot 10 \\
0 \cdot 006 \\
0 \cdot 09 \\
\text { NS } \\
0 \cdot 001 \\
\text { NS } \\
\text { NS } \\
\text { NS }\end{array}$ & $\begin{array}{l}0.96 \\
0.59 \\
1.20 \\
1.21 \\
1.26 \\
0.98 \\
1.07 \\
0.73 \\
0.72 \\
0.99 \\
1.12 \\
1.09 \\
1.17\end{array}$ & $\begin{array}{l}7 \cdot 1 \\
0 \cdot 4 \\
0 \cdot 4 \\
1 \cdot 7 \\
2 \cdot 4 \\
2 \cdot 5 \\
3 \cdot 1 \\
1 \cdot 1 \\
2 \cdot 9 \\
7 \cdot 2 \\
3 \cdot 8 \\
3 \cdot 5 \\
0 \cdot 8\end{array}$ & $\begin{array}{l}0.004 \\
\text { NS } \\
\text { NS } \\
\text { NS } \\
\text { NS } \\
\text { NS } \\
0.06 \\
\text { NS } \\
0 \cdot 09 \\
0.004 \\
0.04 \\
0.05 \\
\text { NS }\end{array}$ & $\begin{array}{l}0.96 \\
0.59 \\
1.20 \\
1.21 \\
1.26 \\
0.98 \\
1.07 \\
0.73 \\
0.72 \\
0.99 \\
1.12 \\
1.09 \\
1.17\end{array}$ \\
\hline
\end{tabular}

${ }^{\star}$ Huynh-Feldt correction values for the repeated measures. Tib $=$ time in bed.

\section{SALIVARY MELATONIN}

During the morning shift, salivary melatonin concentrations declined from $225 \mathrm{pmol} / \mathrm{l}$ at 0700 to $40 \mathrm{pmol} / \mathrm{l}$ at 1100 in the young letter sorters and from $80 \mathrm{pmol} / \mathrm{l}$ at 1700 to 30 $\mathrm{pmol} / \mathrm{l}$ at 1100 in the older sorters (fig 4). At all time points examined, the young sorters had higher melatonin concentrations than the older sorters. During the night shifts, there was a significant main effect of day on salivary melatonin (table 3 ), showing a delay in the onset of melatonin secretion during the consecutive night shifts. In the younger age group, there was a tendency for a later onset of melatonin excretion during the consecutive night shifts. The interaction between age and day was not significant $(p<0.08)$.
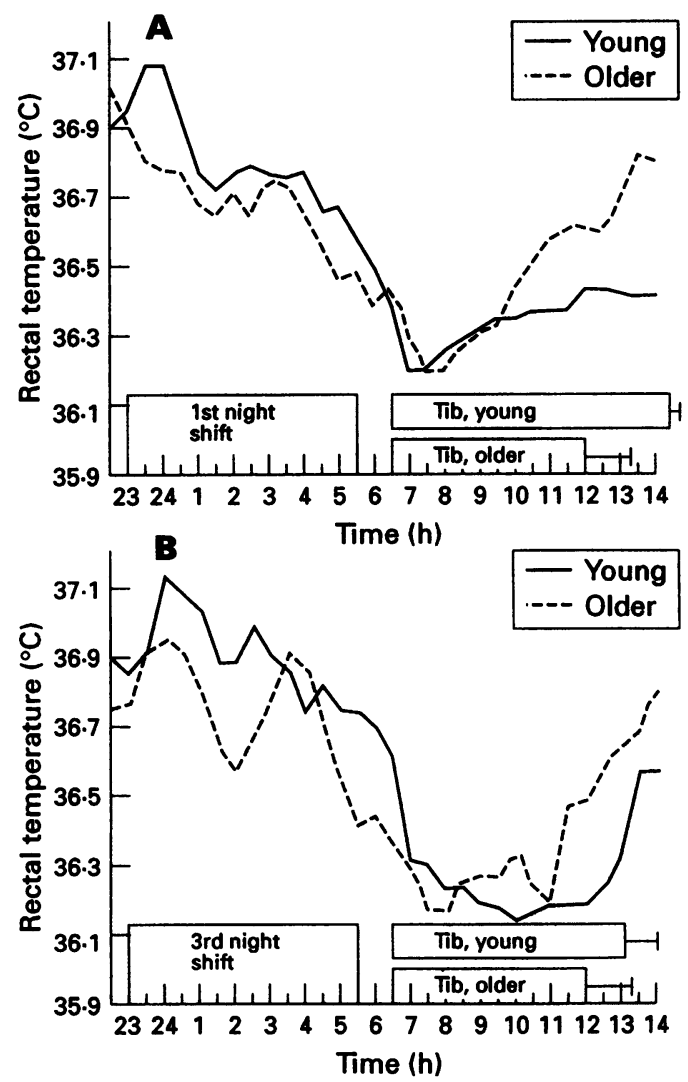

Figure 2 Mean rectal temperature of the young and older subjects during and after the first $(A)$ and the third $(B)$ night shifts; bars are mean starting and ending time of sleep (SEM) of both groups; Tib = time in bed.

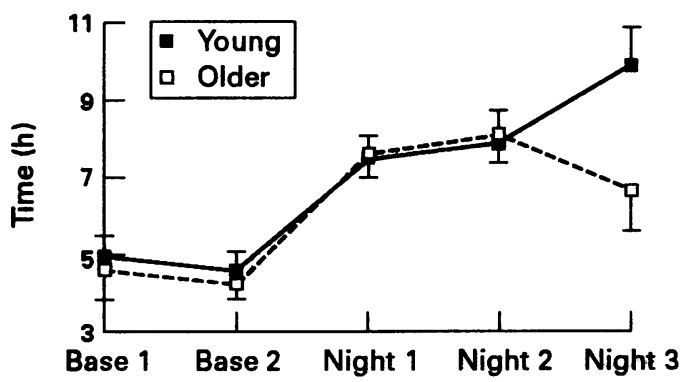

Figure 3 Time of the mean (SEM) rectal temperature minimum of the young and older subjects during the two baseline (base) days and the three consecutive night shifts. 
Figure 4 Mean (SEM) salivary melatonin (MT) excretion of the young and older subjects during one morning (base) and three consecutive night shifts.

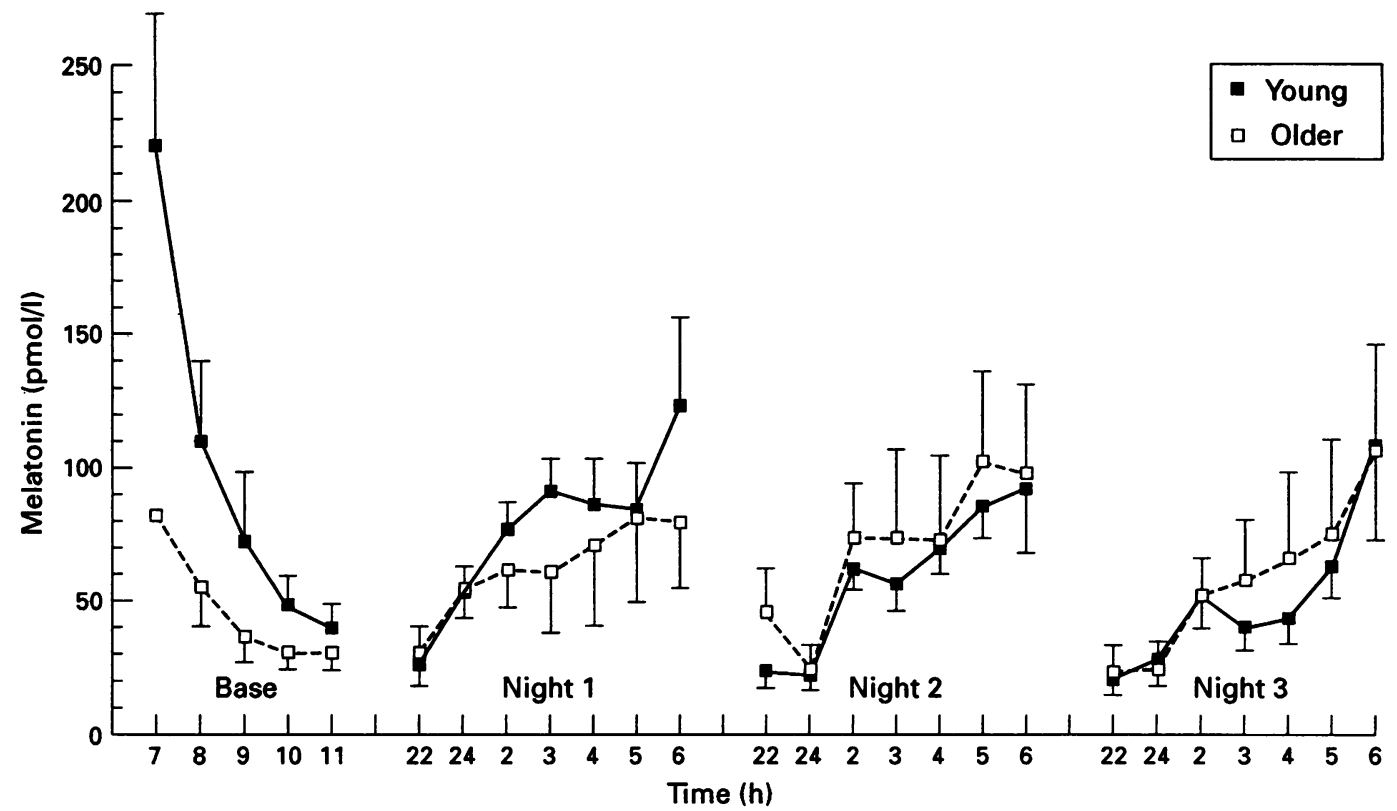

Table 3 Results of analyses of variance with repeated measures on salivary melatonin (MT) and sleepiness (KSS scale): effects of age, day (night shifts), time of the shift, and their interactions

\begin{tabular}{|c|c|c|c|c|c|c|c|c|c|c|c|c|c|c|c|c|c|c|c|c|}
\hline \multirow[b]{2}{*}{ Variable } & \multicolumn{2}{|c|}{$\begin{array}{l}\text { Age } \\
d f=1 / 12\end{array}$} & \multicolumn{3}{|c|}{$\begin{array}{l}\text { Day } \\
d f=2 / 24\end{array}$} & \multicolumn{3}{|c|}{$\begin{array}{l}A g e^{\star} \text { Day } \\
d f=2 / 24\end{array}$} & \multicolumn{3}{|c|}{$\begin{array}{l}\text { Time } \\
d f=6 / 72\end{array}$} & \multicolumn{3}{|c|}{$\begin{array}{l}\text { Time* Day } \\
d f=12 / 144\end{array}$} & \multicolumn{3}{|c|}{$\begin{array}{l}\text { Time* Age } \\
d f=6 / 72\end{array}$} & \multicolumn{3}{|c|}{$\begin{array}{l}\text { Time }{ }^{\star} \text { Day } \\
d f=12 / 144\end{array}$} \\
\hline & $F$ & p Value & $F$ & p Value & $\varepsilon$ & $F$ & p Value & $\varepsilon$ & $F$ & p Value & $\varepsilon$ & $F$ & p Value & $\varepsilon$ & $F$ & p Value & $\varepsilon$ & $F$ & p Value & $\varepsilon$ \\
\hline \multirow{2}{*}{$\begin{array}{l}\text { Melatonin } \\
\text { Sleepiness } \\
\text { (KSS) }\end{array}$} & 0.0 & NS & $3 \cdot 5$ & 0.05 & $1 \cdot 07$ & $2 \cdot 9$ & 0.08 & 1.07 & $12 \cdot 5$ & 0.000 & 0.30 & 1.5 & NS & 0.33 & 0.3 & NS & 0.30 & 0.6 & NS & 0.33 \\
\hline & 0.1 & NS & $6 \cdot 3$ & 0.01 & 0.72 & $4 \cdot 8$ & 0.02 & 0.72 & 24.5 & 0.000 & 0.56 & 0.9 & NS & 0.95 & 1.0 & NS & 0.56 & $4 \cdot 1$ & 0.000 & 0.95 \\
\hline
\end{tabular}

^Huynh-Feldt correction values for the repeated measures.

Figure 5 Sleep duration (SEM) and autonomic sleep phases after the baseline (B) and three consecutive night (N1N3) shifts for young and older letter sorters.

Figure 6 Mean (SEM) sleepiness ratings (KSS scale 1-9) of the young and older subjects during one day and three consecutive night shifts.
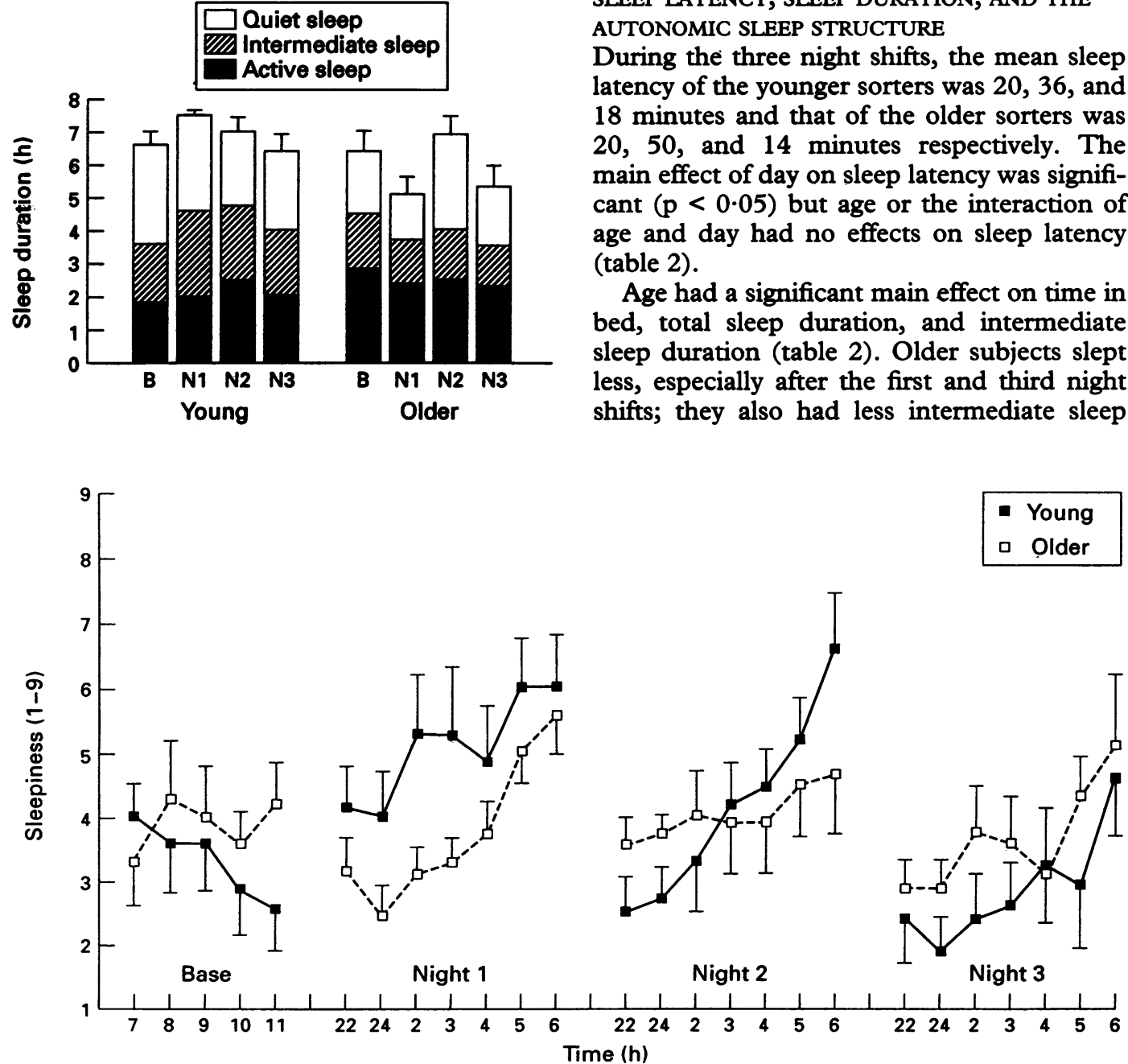
AUTONOMIC SLEEP STRUCTURE

During the three night shifts, the mean sleep latency of the younger sorters was 20,36 , and 18 minutes and that of the older sorters was 20,50 , and 14 minutes respectively. The main effect of day on sleep latency was significant $(p<0.05)$ but age or the interaction of age and day had no effects on sleep latency (table 2).

Age had a significant main effect on time in bed, total sleep duration, and intermediate sleep duration (table 2). Older subjects slept less, especially after the first and third night shifts; they also had less intermediate sleep

SLEEP LATENCY, SLEEP DURATION, AND THE 
Figure 7 Mean (SEM) alertness ratings (scale 1-13) before and after sleep for the young and older subjects; one sleep after the day shift (baseline $B$ ) and three sleeps after the night shifts (N1-N3).

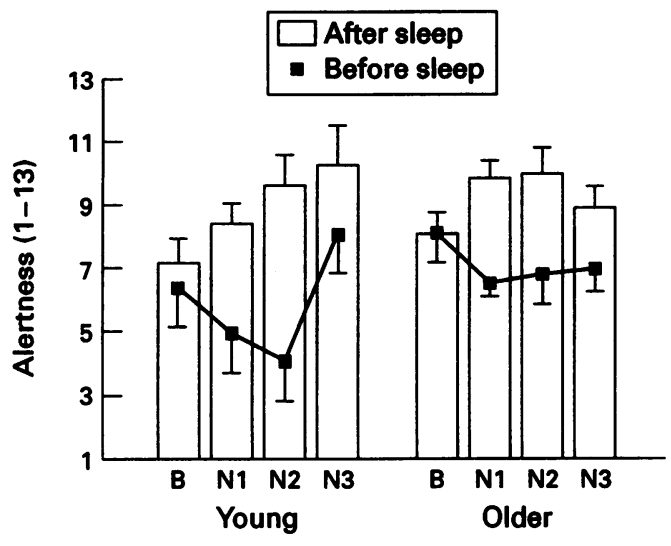

(fig 5). The interaction between age and day in time in bed was not, however, significant $(p<0.06)$. There were no differences in the number of movements ( $<10 \mathrm{~s}$ and $>10 \mathrm{~s}$ ) during the sleep between the groups or days.

PERCEIVED QUALITY OF SLEEP AND SLEEPINESS There was a significant main effect of day (night shifts) on alertness before the sleep ( $p<0.001)$ and on sleepiness (KSS) during the night shifts $(p<0.01$; tables 2-3). Sleepiness decreased mostly in the younger sorters during the subsequent night shifts (fig 6). Age had no significant main effect on sleepiness or sleep quality, but the interaction of age and day (night shifts) was significant for several variables: alertness before the sleep $(\mathrm{p}<0.01)$, alertness after the sleep $(p<0.05)$, the refreshing effect of sleep $(p<0.05)$, and sleepiness during the night shifts ( $<<0.05$; tables 2 and 3, fig 7). The younger sorters were more sleepy than the older sorters during and after the first night shift but less sleepy during and after the third night shift.

\section{Discussion}

Research interest on ageing and work has increased during the recent years; partly due to growing economical and occupational problems of the ageing process, partly due to insufficient knowledge. Most studies dealing with ageing and shiftwork have been nonexperimental. ${ }^{1-3}$ Consequently, the reasons and mechanisms behind the greater sleep disturbances in older shift workers have remained unclear.

Long term follow up studies in experimental sleep research are extremely difficult to conduct. Consequently, causative research on ageing is difficult. In cross sectional studies of ageing, like the present one, methodological problems often arise from the healthy worker effect due to the selection of workers and due to the fact that it is often difficult to firmly establish that the differences found between the age groups are caused by the ageing process itself.

In the present study, the young and older letter sorters did not differ with respect to sex, introversion/extroversion or neuroticism, ${ }^{29}$ flexibility of sleeping habits, or ability to overcome drowsiness. ${ }^{30}$ Although shiftwork experience was greater in the older subjects (averaging 17 years compared with three years in the young subjects), both groups were experienced shift workers. In both groups, two out of seven subjects were reported to snore "very loudly" but the groups did not differ in relation to snoring, body weight, or body mass index. Although there is suggestive evidence from large surveys ${ }^{31}$ that sex and age effects may interact in determining the incidence of insomnia in day workers, the possible interaction of age and sex is unlikely in this experimental study with controlled conditions.

Because ageing is connected to increased "morningness" 32 and, on the other hand, "morningness" is related to slower circadian adjustment to night work ${ }^{33}$ the possible differences in "morningness" or in the circadian phase before the studied night shifts could be important. Both groups were, however, synchronised to the same sleep-wakefulness rhythm during the two baseline days before the consecutive night shifts and the groups showed absolutely no difference in the mean phase of the body temperature circadian rhythm during the baseline. According to the questionnaire of "morningness/eveningness" (diurnal type scale ${ }^{32}$ ) the older subjects were, however, slightly (NS) more morning types (mean score $2 \cdot 3$ ) compared with the younger group (mean score $2 \cdot 9$, scale $1-5$ ). Although the statistical testing of confounding factors between selected small study groups is not relevant, the difference was small and in respect of the finding of no difference in circadian rhythm of body temperature during the baseline period, unlikely to account for the statistically significant differences found between the groups.

The main result of the present study was that the young shift workers were more sleepy than the old shift workers during and after the first night shift, but less sleepy during and after the third night shift. According to a three process model of sleepiness, ${ }^{34}$ sleepiness during night shifts is mainly dependent on homeostatic and circadian factors. During the first night shift, there were no differences in the circadian rhythm of body temperature between the groups. As there were also no differences in the amount of sleep before the first night shift it seems probable that the older subjects were less sensitive to acute sleep deprivation caused by the first night shift. In some earlier studies, 910 older subjects have similarly been found to be less sensitive to experimental sleep deprivation. The reasons behind the increased resistance of the older shift workers to acute sleep deprivation can only be speculated on. They could be developmental or simply due to the healthy worker effect. A long shiftwork experience, as in the older group of this study, means that no major medical problems have arisen during the past years.

Despite a shorter time in bed and rather different sleep structures the older shift workers still felt more alert and more refreshed 
after the first and second night shifts than did the younger workers. Bonnet ${ }^{35}$ has studied the performance and sleepiness of young and older adults after experimentally disturbed sleep. Instead of similar sleep disturbances, the older subjects tended to have less performance deterioration on morning testing after the experimental sleep disturbance than did the young adults. The results of Bonnet thus support the present results and imply that ageing effects on sleep may be developmental rather than degenerative."

During the three consecutive night shifts, the sleepiness of the younger sorters decreased constantly while that of the older sorters did not change. At the same time, the body temperature rhythm of the younger sorters became phase delayed while that of the older sorters did not change (a significant age and day interaction in sleepiness and body temperature. Because the modification of sleep structure during the night shifts was not dependent on age, it seems obvious that the higher alertness of the young sorters during the last night shift was due to a faster circadian adjustment. According to earlier studies, there are indications of slower circadian adjustment of the oral temperature rhythm in middle aged shift workers, than in young shift workers. ${ }^{1213}$

We conclude that the young and old shift workers show pronounced differences in their adaptation to night work. During the first and second night shifts, the older workers cope better than the younger workers. After three consecutive night shifts, however, ageing seems to increase sleepiness due to an insufficient circadian adjustment.

The present study was carried out in the laboratory with controlled conditions. In the community, the sleep of shiftworkers is greatly disturbed by environmental and domestic factors. Although older shiftworkers tend to have better housing (and sleeping) conditions and fewer domestic responsibilities, the older shiftworkers' sleep disturbances are probably greater in natural conditions compared with the present laboratory conditions with good sleeping facilities. We suggest that continuous night work should be voluntary for older shift workers because of physiological ageing.

1 Foret J, Bensimon G, Benoit O, Vieux N. Quality of sleep as a function of age and shift work. In: Reinberg A, Vieux N, Andlauer $\mathbf{P}$, eds. Aspects of human efficiency. London: English Universities Press, 1981:273-82.

2 Koller M. 1983. Health risks related to shift work. Int Arch Occup Environ Health 1983;53:59-75.

3 Ákerstedt T, Torsvall L. Shiftwork. Shift-dependent wellbeing and individual differences. Ergonomics 1981;24: 265-73.

4 Reiter RJ. The ageing pineal gland and its physiological consequencies. Bioessays 1992;14:169-75.

5 Van Good WA, Mirmiran M. Ageing and circadian thythms. In: Gool WA, Van Haaren F, eds. Progress in brain research. New York: Elsevier, 1986:255-77.

6 Zulley J. Free-running circadian rhythms in ageing. Sleep Research 1992;1(suppl):260.
7 Lieberman H, Wurtman J, Teicher M. Circadian rhythms of activity in healthy young and elderly humans. Neurobiol Ageing 1989;10:259-65.

8 Miles LE, Dement WC. Sleep and ageing. Sleep 1980;3: 119-20.

9 Fröberg J, Karlsson CG, Levi L, Lindberg L. Circadian variations in performance, psychological ratings, catevariations in performance, psychological ratings, catesleep deprivation. In: Colquhoun WP, eds. Aspects of sleep deprivation. In: Colquhoun WP, eds. Aspects of human efficien

10 Webb WB, Agnew HW. The effects of a chronic limitation of sleep length. Psychophysiology 1974;11:265-74.

11 Bonnett MH, Rosa RR. Sleep and performance in young adults and older normals and insomniacs during acute sleep loss and recovery. Biol Psychol 1987;25:153-72.

12 Härmä MI, Knauth P, Ilmarinen J, Ollila $H$. The relation of age to the adjustment of the circadian rhythms of oral temperature and sleepiness to shift work Chronobiol Int 1990;7:227-33.

13 Matsumoto K, Morita Y. Effects of night-time nap and age on sleep patterns of shiftworkers. Sleep 1987;10:580-9.

14 Torsvall L, Ákerstedt T, Gillberg M. Age, sleep and irregular workhours. A field study with electroencephalographic recordings, catecholamine excretion and self-ratings. Scand $\mathcal{f}$ Work Environ Health 1981;7 196-203.

15 Walsh JK, Sugerman JL, Muehlbach MJ, Schweitzer PK. Physiological sleep tendency during sleep-wake schedule inversion in young and middle-age adults. Sleep Research 1987;16:653

16 Webb WB. A further analysis of age and sleep deprivation effects. Psychology 1985;22:156-61.

17 Härmä M, Laitinen J, Partinen $M$, Suvanto $S$. The effect of 4-day round flight over 10 time zones on the circadian variation of salivary melatonin and cortisol in flight variation of salivary melatonin and

18 Miles A, Philbrick D, Tidmarch SF, Shaw DM. Direct radioimmunoassay of melatonin in saliva. Clin Chem 1985;31:1412-3

19 Alihanka J. Sleep movements and associated autonomic nervous activities in young male adults. Academic dissertion. Acta Physiol Scand 1982;511(suppl):1-85.

20 Alihanka J. Basic principles for analyzing and scoring Bio-matt (SCSB) recording. Turku: The University of Turku, 1985. (D Medica; No 26.)

21 Hasan J, Alihanka J. Construction of REM-NREM sleep hypnograms on body movements recordings. In: Koella Wypnograms on body movements recordings. In:

22 Montagna $P$, Liquori $R$, Zucconi M, Forza E, Lugares A, Cirignotta F, Lugaresi E. Physiological hypnic myoclonia. Electroencephalography and Clinical Neurophysiology 1988;70:172-6.

23 Kaartinen J, Lyytinen $H$. Motor adaptation to a change in sleep conditions. In: Hgyppâ M, ed. Nordic sleep research. Turkey: Social Insurance Institution, 1990

24 Pulli $K$, Härmä $M$, Hasan J, Värri $A$ and Loula $P$. The relationship between autonomic activity measured by SCSB and delta activity during sleep. fournal of Sleep Research 1994 (in press).

25 Åkerstedt T, Hume K, Minors D, Waterhouse J. The subjective meaning of good sleep-a longitudinal approach and an index. Perceptual and motor skills (in press)

26 Åkerstedt T, Gillberg M. Subjective and objective sleepiness in the active individual. Int $¥$ Neurosci 1990;52 ness in

27 Winer BJ. Statistical principles in experimental design. New York: McGraw-Hill Book Company, 1971

28 Huynh H, Feldt LS. Estimation of the box correction for degrees of freedom from sample data in the randomized block and split plot designs. Fournal of Educational Statistics 1976;1:69-82.

29 Eysenck HJ, Eysenck SBG. Manual of the Eysenck personality inventory. London: University of London Press, 1964.

30 Folkard S, Monk TH, Lobban MC. Toward a predictive test of adjustment to shiftwork. Ergonomics 1979;22 79-91.

31 Kripke DF, Simons RN, Garfinker L, Hammond C. Short and long sleep and sleeping pills. Arch Gen Phychiatry 1979;36:103-16.

32 Torsvall L, Ákerstedt T. A diurnal type scale. Construction, consistency and validation in shift work. Scand 7 Work Environ Health 1980;6:283-90.

33 Härmä M, Waterhouse J, Minors DS, Knauth P. The effect of masking on circadian adjustment and interindividual differences on a rapidly rotating shift individual differ WO

34 Folkard S, Akerstedt TB. A three-process model of the regulation of alertness-sleepiness. In: Broughton $\mathrm{RJ}$, Ogilvie RD, eds. Sleep, arousal, and performance. A tribute to Bob Wilkinson. Boston: Birkhäuser, 1992.

35 Bonnet MH. The effect of sleep fragmentation on sleep and performance in younger and older subjects. Neurobiol Aging 1988;10:21-5. 